\title{
P320: Epidemiological study drug administration routes (DAR) in the department of pediatrics Gabriel Touré hospital, Mali
}

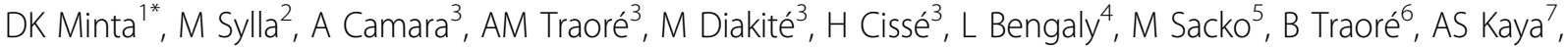 \\ AT Sidibé ${ }^{7}$, HA Traoré ${ }^{7}$, T Sidibé $^{2}$, MM Keita $^{4}$
}

From 2nd International Conference on Prevention and Infection Control (ICPIC 2013)

Geneva, Switzerland. 25-28 June 2013

\section{Introduction}

Injectable route seems to be the most frequently used in health facilities in resource-limited.

\section{Objectives}

In order to better understand this issue still under documented, we conducted a longitudinal study of DAR use in the general pediatric ward of the Gabriel Touré Hospital to Bamako during 6 months.

\section{Methods}

We are interested in the routes of administration applied to a population of 300 children with a sex ratio $(\mathrm{M} / \mathrm{F})=$ 1.3. Their average age was 2 years \pm 1 .

\section{Results}

Assumptions diagnostic from the admission to discharge patients underwent a change both their frequency and their formulation as well malaria $(37.4 \%$ vs $39.7 \%$ at 72 hours), pneumonia ( $19 \%$ vs $20 \%$ at 72 hours), and nephrotic syndrome $(2.2 \%$ vs. $5.1 \%$ in 72 hours) occurred most commonly mentioned.

Treatments were prescribed according to the diagnostic were administered per injection route at admission (76.6\%) to72th hours (70\%) and the output (36.3\%). Complications were noted inflammation of the catheter puncture sites $(21.8 \%)$ at admission, $18 \%$ after 5 days of hospitalization, the abscess puncture MI (2.1\%). The mean duration of hospitalization recorded was $7.6 \pm 3.7$ days and lethality was $11 \%$.

\section{Conclusion}

Injection is the most widely used in the pediatric unit III in connection with the most common pathologies. A detailed study would be needed to assess the adequacy of the diagnostic hypotheses and routes of administration. The injection volume exposed to the risk of Accidental exposure to blood staff and patients.

\section{Disclosure of interest}

None declared.

\section{Author details}

${ }^{1}$ Ministère de la santé, Hôpital Gabriel Touré, Bamako, Mali. ${ }^{2}$ Service de Pédiaterie, CHU Gabriel Touré, Bamako, Mali. ${ }^{3}$ Services de Maladies infectieuses, CHU du Point G, Bamako, Mali. ${ }^{4}$ Service de Pharmacie Hospitalière, CHU Gabriel Touré, Bamako, Mali. ${ }^{5}$ Département de Santé publique, Faculté de Médecine, Université de Bamako, Bamako, Mali.

${ }^{6}$ Servide de Pédiaterie, CHU du Point G, Bamako, Mali. ${ }^{7}$ Service de Médecine interne, CHU du Point G, Bamako, Mali.

Published: 20 June 2013

doi:10.1186/2047-2994-2-S1-P320

Cite this article as: Minta et al:: P320: Epidemiological study drug administration routes (DAR) in the department of pediatrics Gabriel Touré hospital, Mali. Antimicrobial Resistance and Infection Control 2013 2(Suppl 1):P320.

${ }^{1}$ Ministère de la santé , Hôpital Gabriel Touré, Bamako, Mali

Full list of author information is available at the end of the article

C 2013 Minta et al; licensee BioMed Central Ltd. This is an Open Access article distributed under the terms of the Creative Commons 